\title{
De casadas a divorciadas. Separaciones, divorcios y nulidades matrimoniales en la sociedad colonial, Audiencia de Charcas, 1595-1640 ${ }^{1}$
}

\author{
Ana María PRESTA \\ Universidad de Buenos Aires - CONICET \\ ampresta@filo.uba.ar
}

Recepción: 21 de diciembre de 2015 / Revisión: 9 de abril de 2016

Aceptación: 15 de mayo de 2016 / Publicación: Diciembre de 2016

\begin{abstract}
RESUMEN
Los crímenes y delitos perpetrados entre los esposos en la esfera privada rara vez se hacían públicos o conducían a la separación más allá de las diferencias e iniquidades que el deber obligaba a tolerar. El matrimonio, luego del Concilio de Trento, se convirtió en un lazo indisoluble, excepción hecha del fallecimiento de uno de los cónyuges. Sin embargo, existen voces femeninas que, tras los documentos notariales, expresan la desilusión, el descontento y el dolor por el maltrato, el adulterio y el engaño y que, esperanzadas en el tenue amparo eclesiástico ante la ruptura de un vínculo sacramental, recurren a la justicia y al derecho canónico solicitando la separación conyugal, el divorcio, o la nulidad del matrimonio.
\end{abstract}

Palabras clave: matrimonio, separación, divorcio, nulidad, Perú, siglos XVI-XVII.

From Wives to Divorcees. Separation, Divorce and Marriage Annulment in Colonial Society, Audiencia de Charcas, 1595-1640

\begin{abstract}
Marital crimes and offenses perpetrated in the private sphere were only rarely made public or led to separation, beyond the tolerated differences and iniquities obligated by duty. After the Council of Trent, matrimony became indissoluble, except in case of death of one of the spouses. Notarial documents reveal, nevertheless, the existence of female voices -expressing disappointment, discontent and pain due to abuse, adultery and betrayal- that resorted to Canon Law and justice in order to request separation, divorce or marital annulment, hopeful of acquiring ecclesiastical protection in light of the rupture of a sacramental bond.
\end{abstract}

Keywords: Marriage, Separation, Divorce, Annulment, Peru, 16-17 $7^{\text {th }}$ Centuries.

SuMARIO: 1. Introducción. 2. Las presentaciones de separación, divorcio y nulidad en La Plata. 3. Conclusiones. 4. Referencias bibliográficas.

1 Este artículo forma parte del Proyecto I+D HAR2012-35197 del Ministerio de Economía y Competitividad de España, Justicia Eclesiástica y conformación de la sociedad en América hispana colonial. Una versión preliminar se presentó en el Simposio "Entre lo global y lo autóctono: justicia eclesiástica y sociedad en la América ibérica colonial” en el marco del XVII Congreso Internacional de AHILA, Berlín, 2014. 


\section{INTRODUCCIÓN}

Mientras que el matrimonio y la familia en América colonial, y específicamente en el Virreinato del Perú, suscitaron reflexión y producción académica, la ruptura del vínculo sacramental por otras motivaciones que no fuera la muerte de uno de los cónyuges constituye un tema en que la disponibilidad, cortedad y continuidad de las fuentes lo hace historiográficamente esquivo, cuando también excepcional ${ }^{2}$. Es real que el nombrado divorcio en los largos siglos coloniales constituyó una excepción más que la norma resultante del distanciamiento de los esposos, quienes podían solicitarlo frente a insalvables dificultades de convivencia como la ausencia de la vida maridable u ofensas y delitos graves, problemas que podían llevar a la separación o a la nulidad del vínculo, todo lo cual debía dirimirse en la justicia eclesiástica. Las más de las veces, la violencia, los abusos, el maltrato, el adulterio y hasta la impotencia sexual permanecían en los pliegues del ámbito privado sin ingresar a la esfera legal, dando lugar a separaciones informales.

Las fuentes sobre las separaciones, las denuncias acerca de las transgresiones al vínculo y la concesión del divorcio en la primera centuria del dominio colonial, en la que se asienta esta investigación, son escasas y esquivas, por cuanto esos documentos están perdidos en los archivos eclesiásticos como en aquellos civiles que guardan los expedientes judiciales en diferente grado delictual, de presentación, seguimiento y apelación. No obstante ello, la labor desarrollada durante décadas en los repositorios bolivianos y europeos me permitió recoger poco más de una veintena de presentaciones que concentran los trazos y retazos de las solicitudes de divorcio y, excepcionalmente, copia de las demandas judiciales y las causas incoadas por habitantes de la sede de la Real Audiencia de Charcas. ${ }^{3}$ Esos expedientes, protocolos notariales, en su mayoría, contribuyen a develar los inconvenientes y las complejidades de esas presentaciones, tras las que en ocasiones surgen los sentimientos, pasiones y sufrimientos personales de los involucrados junto a los requisitos de admisión de los casos por parte de la justicia eclesiástica. Más allá de las diferencias de clase y etnia que se detectan en las demandas, se observan las iniquidades de género visibles tras la condición jurídica de la mujer y los prejuicios adicionales que conllevaba su deseo de separación junto a las contrariedades de mantenerse fuera del hogar conyugal y romper la obligada vida maridable al abandonar el hogar común.

\footnotetext{
2 En el ámbito virreinal peruano y en jurisdicciones cercanas han abordado el tema Flores GALINDO Chocano, 1984, pp. 403-422; Lavallé, [1986] 1999, pp. 19-66; StaViG, 1984, pp. 428-430; 1996; CAVIERES - SAlinas, 1991, pp. 77-116; SALinas, 1991, pp. 37-67 y 1994, pp. 173-192; MallO, 1992, pp. 373-400; GoNZÁleZ DEL Riego, 1995, pp. 197-217 y 1999, pp. 131-142; MeJia CARrillo, 1997, pp. 57-62; RoJas, 1999, pp. 89-116; Bustamante Otero, 2001, pp. 109-160; Kluger, 2003a, pp. 131-151; 2003b, pp. 525-544 y 2004, pp. 229-236; Ghirardi, 2004, pp. 217-417; VAn Deusen, 2007, pp. 139-166; Franchin, 2009.

3 Charcas refiere a la porción meridional del Virreinato del Perú. El que fuera territorio audiencial configura hoy, con escasas variantes, el del Estado Plurinacional de Bolivia. La Audiencia fue creada por el Rey Felipe II en 1559 e inaugurada en 1561 en la ciudad de La Plata, primera urbe española en territorio sur andino, fundada en 1540 con ese nombre por la cercanía al mineral argentífero de Porco, asiento minero ubicado en el cercano altiplano donde en 1545 se descubriera el Cerro Rico de Potosí. La ciudad de La Plata también se nombra Chuquisaca o Charcas y hoy es Sucre, capital histórica de Bolivia.
} 
Valga destacar que quienes en este trabajo se presentan buscando romper el vínculo matrimonial son, en su abrumadora mayoría, mujeres casadas en la segunda mitad del siglo XVI, lo cual otorga relevancia a esta investigación en tanto la reforma tridentina, que hizo del matrimonio un sacramento único e indisoluble en 1563, distaba de tener escasos cincuenta años de vigencia normativa y práctica efectiva cuando las demandantes utilizaron la herramienta del divorcio para sortear un matrimonio desdichado.

\section{LAS PRESENTACIONES DE SEPARACIÓN, DIVORCIO Y NULIDAD EN LA PLATA}

Entre 1595 y 1640, veinte y una mujeres hicieron protocolizar sus demandas de separación, divorcio o nulidad matrimonial en la ciudad de La Plata, sede de la Real Audiencia de Charcas y del arzobispado del mismo nombre. De ellas, una respondía con la propia a la previa efectuada por su marido, tal como lo marcaba la apertura de un caso, y solamente tres mujeres legítimamente casadas solicitaban la anulación del vínculo. Asimismo, y al momento de testar, un varón confirmaba su separación de hecho y advertía de la solicitud formal que más de dos décadas atrás había efectuado quien aún era su esposa ${ }^{4}$. El mayoritario porcentaje de esposas que demandan separación ha dado lugar a sostener que el "divorcio es una institución femenina" afirmación, lejos de concentrar los prejuicios de género pasados y presentes, o aludir a la emocionalidad e impulsividad femeninas, puede leerse como una práctica o solución extrema de la que hacían uso las mujeres para sortear convivencias desdichadas. La mera presentación de una causa de divorcio llevaba a las esposas a desafiar las iniquidades de género y a dar a conocer públicamente, al necesitar procuradores y testigos que avalaran sus demandas, las desventuras que les aparejaba el matrimonio.

En los albores del siglo XVII, mujeres de diferentes estratos sociales y étnicos abrazaron con determinación y valentía la posibilidad de apartarse de la cohabitación matrimonial al echar mano del divorcio, una herramienta ajustada al Derecho canónico que les permitía limitar temporalmente o poner punto final a ofensas como la sevicia, las injurias, el adulterio y el dolo cometidos por maridos que, además, a menudo vivían a expensas del patrimonio dotal o del trabajo y sudor de sus esposas. La superioridad jurídica masculina y la ideología patriarcal, sostenidas culturalmente y consagradas por la ley, permitían a maridos licenciosos o escasamente comprometidos con el matrimonio a hacerlo perdurar más allá del incumplimiento de las obligaciones que conllevaba el sacramento.

\footnotetext{
4 Aunque cincuenta años más tarde, Bernard Lavallé advierte la misma tendencia en las solicitudes de divorcio que estudió para el Arzobispado de Lima. Cf. LAVALLÉ, [1986] 1999, pp. 24, 29. De igual modo lo observaron Alberto Flores Galindo y Magdalena Chocano para la misma jurisdicción, Flores GALINDO - CHOCANO, 1984, pp. 403-422, y M. Mónica Ghiradi, para Córdoba, en el siglo XVIII, GHIRARDi, 2004, pp. 312-315. Esa misma conducta femenina la destacaron en México colonial, entre otros, ArRom, 1985, p. 206 y PESCADOR, 1994, p. 202. Para México y el Río de la Plata tardo colonial, cf. Dávila Mendoza, 2004 y Mallo, 1992.

5 Perrot, 1989, pp. 288-290.
} 
Las presentaciones de divorcio dejan entrever con claridad que tanto las mujeres como los hombres de las élites asumían el vínculo como un contrato económico, con cuya indisolubilidad intentaban lidiar más allá de toda falta que lesionara la convivencia, el respeto mutuo y la equidad entre los cónyuges. A las mujeres de la élite les preocupaba la malversación de su dote y la recuperación de su patrimonio luego de la separación; a las desposadas con funcionarios menores, dependientes de los ingresos masculinos, les costaba sobrevivir una vez presentada la demanda, razón por la cual resolvían el retorno al hogar conyugal para intentar una mejor convivencia; aquellas que se ganaban la vida a diario destacaban su esfuerzo, buscaban inhibir el acceso de sus maridos a sus bienes y ganancias, mientras sostenían causas incoadas en la justicia más allá del tiempo transcurrido desde la iniciación y la falta de sentencia. Por todo ello, desde una perspectiva de género, el divorcio puede visualizarse más que como "institución" como una opción o, en otras palabras, como "asunto", "recurso" o "iniciativa" femenina frente a la violencia y el maltrato masculinos ${ }^{6}$. También, y desde la misma perspectiva, la solicitud de divorcio constituía un desafío femenino al patriarcalismo y a las normas sociales inscriptas en el habitus, en tanto la demanda de separación ponía en tela de juicio desde la "minoridad de la mujer", consagrada por la costumbre y la ley y refrendada por las instituciones, a la ilimitada autoridad de un esposo sobre su cónyuge y su descendencia, al tiempo que cuestionaba el derecho de "propiedad" que un hombre tenía sobre "su mujer"7.

Vecinas, residentes o estantes en la ciudad cabecera de Sur andino, las demandantes, salvo cuatro excepciones, exponían escuetamente su solicitud de separación sin explicitar los motivos reales de su presentación, en tanto apelaban a una fórmula de protocolo que resguardaba la intimidad del matrimonio, o lo que quedaba del, y permitía la continuidad de la convivencia hasta que no mediara la aceptación del caso por el juez eclesiástico quien, inicialmente, procedía a ordenar el depósito o guarda de la esposa en la casa de un vecino honorable o en algún monasterio o recogimiento mientras durase el juicio, situación que, más allá de los perjuicios económicos y la segura alienación individual y social, permitía a la mujer litigar en seguridad e integridad, sin soportar la constante coerción, el hostigamiento o el ultraje del marido ${ }^{8}$. La fórmula inscripta como justificación de la solicitud de separación o divorcio rezaba, "por las causas y razones que ya informaré" o, sumando al marido y su consentimiento, "por ciertas causas y razones que tengo tratadas con él", lo cual auguraba un mutuo consentimiento favorable al rescate de los bienes propios y dotales y a la saludable recuperación de los comunes, si los hubiera. Las causas iban a exponerse a lo largo del pleito, si prosperaba la presentación, en el cual no sólo deponían los cónyuges, sino sus testigos, a menudo familiares, conocidos, vecinos y sirvientes,

\footnotetext{
${ }^{6}$ Apelando a los malos tratos que recibían las mujeres en el matrimonio, Nizza DA Silva, 1991, p. 341, apela al concepto de "feminización" para caracterizar el proceso de divorcio, mientras que ARROM, 1985, p. 206 juzga al divorcio como "recurso femenino", GHIRARDI, 2004, p. 312, lo califica como "asunto" y CosTA, 2008, p. 4, como una "iniciativa más femenina".

7 Bourdieu, 1977, p. 73; 1980, pp. 52-65.

8 Arrom, 1985, pp. 212-215; Langue, 2005, pp. 7, 11; GÁlvez Ruiz, 2006, pp. 76-77; Arroyo VozmeDIANO, 2008, pp. 132, 141; VAN DEUSEN, 2007, pp. 108-112, presenta en su investigación el Recogimiento o Casa de Divorciadas de Lima fundado en 1589 a imagen de sus precedentes europeos, aparecidos luego del Concilio de Trento, para contener y albergar a mujeres caídas o necesitadas de refugio.
} 
conforme a la condición social de los involucrados y a la naturaleza y gravedad de cada caso.

Diez y nueve de las presentaciones a las que aludo se hallaron en las Escrituras Públicas de la ciudad de La Plata guardadas en el Archivo y Biblioteca Nacionales de Bolivia, Sucre, una en el Archivo Arquidiocesano Monseñor Taborga de la misma ciudad capital y la restante en los fondos de la Inquisición del Archivo Histórico Nacional en Madrid. Tanto las presentaciones ante la autoridad eclesiástica, las respuestas de las partes demandadas, los descargos y testimonios de los testigos, al igual que las sentencias de los vicarios generales para el siglo XVI y gran parte del XVII y que debieran guardarse en el Archivo Arquidiocesano están perdidas, estimándose numerosas puesto que La Plata era, desde 1609, la sede arzobispal regional, incluyendo a los sufragáneos obispados de Nuestra Señora de La Paz, Santa Cruz de la Sierra, Tucumán, Paraguay y Buenos Aires, que habrán sumado cantidad de presentaciones.

En el orden colonial, divorcio significaba la irremediable lesión y ruptura del vínculo matrimonial autorizada por el Derecho canónico y presentaba dos variantes, la nulidad o divorcio quoad vinculum, cuando se establecía la disolución del lazo sagrado o se demostraba que éste no había existido por ausencia de consumación, concediendo nueva aptitud nupcial para ambos cónyuges; y la separación de cuerpos, también conocida como de lecho y mesa o divorcio quoad thorum et mutuam cohabitationem. En esta última variante, el vínculo persistía entre los apartados o separados de hecho, aunque sin permitir la reincidencia matrimonial para los también nombrados divorciados ${ }^{9}$. Ambas instancias eran de difícil concreción y, de obtenerse respuesta favorable a la solicitud de separación o nulidad, mediaban años entre la demanda y la sentencia. Aunque a finales del Antiguo Régimen, Marie Costa estima que el divorcio o separación podía revestir carácter informal o formal. El divorcio informal, cuyas causas podían ser equivalentes a las de un acto formal, sorteaba la intervención de la justicia, lo que lo convertía en acto ilegal. A pesar del carácter delictual que confería a esta práctica la autoridad y las mismas leyes eclesiásticas, las familias la preferían para evitar largos procesos y quedar expuestos públicamente los problemas de orden privado que no deseaban ventilar. Igualmente, los arreglos extrajudiciales y las separaciones de hecho evitaban erogaciones e indefiniciones procesales, a la par que evitaban el daño moral y material de los cónyuges. En ocasiones y en jurisdicciones específicas, el divortium de lecho y mesa, o separación formal o legalizada conferida por un Tribunal Eclesiástico, daba cuenta de que más de la mitad de las parejas que lo habían obtenido se habían separado una y más veces de manera informal ${ }^{10}$.

La demanda formal debía efectuarse ante el tribunal eclesiástico en la sede arzobispal, la charqueña en este caso, o ante la autoridad religiosa correspondiente en las jurisdicciones dependientes. En el escrito de rigor, los demandantes debían exponer sus datos personales, filiación familiar y étnica, para luego dar cuenta de los motivos que habían generado la presentación. Al cónyuge que iniciaba la demanda le com-

9 Rípodas Ardanaz, 1977, pp. 382-392; Molina, 1985, pp. 114-121, 309-312; Arrom, 1985, pp. 208210; Ghirardi, 2004, pp. 218-224; GHIRARDi - LóPEZ IrigOYen, 2009, pp. 246, 253-254.

10 Ghirardi, 2004, p. 221, 228; Costa, 2008, pp. 3. 
petía imponer de la información correspondiente al tribunal para que éste, prima facie, decidiera si el caso era pasible de ingresar para su evaluación a las instancias de dictamen, para luego remitirse a la Santa Sede, en caso de existir la posibilidad de conceder la nulidad.

Los rastros hallados en los protocolos de La Plata, y que parecen constituir el inicio o un refuerzo de las presentaciones eclesiásticas en el espacio secular, son los que permiten seguir, en contados casos, las trayectorias de las nombradas separadas, divorciadas y, excepcionalmente, de aquellas mujeres que habían conseguido la nulidad del vínculo. Las presentaciones femeninas de divorcio estaban exceptuadas de la licencia marital correspondiente, dado que el directo involucramiento del esposo en la causa hacía a la libertad de la demandante para efectuar su presentación ${ }^{11}$. Frente a las tensiones matrimoniales generadas por un divorcio en ciernes, el contrato económico marital aparecía con nitidez en tanto la esposa en depósito tenía derecho a la manutención sin cohabitar en el hogar conyugal, pudiendo reclamar sus bienes y dote y sortear, mediante licencia avalada por la autoridad civil y otorgada en favor de su procurador o algún familiar, la mediación del esposo para realizar transacciones o administrar sus propiedades. El alcalde ordinario, administrador secular de la justicia en primera instancia dentro del espacio municipal, o algún regidor, podían proveer de licencias para otorgar poderes, en tanto la minoridad femenina inhibía toda manifestación legal, excepto el reclamar por malos tratos, denunciar violencia doméstica, advertir sobre la malversación de su dote o dar a conocer crímenes de envergadura que lesionaran su persona o la de terceros. Así, María Flores de Quiñones, mujer de Francisco de Torres, residente en La Plata, se hacía presente en casa del Licenciado Tudela, relator de la Real Audiencia de Charcas, a fin de revocar el poder que para cobranzas y general administración había otorgado a su marido porque "por causas que han sucedido entre ellos, le tiene puesto pleito de divorcio y no es justo que tratándose entre ellos el dicho pleito use de los dichos poderes", los que ahora revertía en su representante legal ${ }^{12}$. En 1603 y ante el notario Simón de Ledesma se presentaba Isabel de Almeida, vecina de Potosí, quien trataba pleito de divorcio y apartamiento contra su marido Joan Arauz de Solís, y en su afán de dar poder a personas que acudieran a sus pleitos y cobranzas, lo otorgaba en un cura y un particular, justificando lo hacía "por ser sola y no tener marido", eufemismo que encubría su separación de hecho y la necesidad de protegerse contra cualquier malversación o eventualidad administrativa que involucrara al cónyuge del cual pretendía desvincularse ${ }^{13}$.

Una vez emitido el escrito suplicatorio, el cónyuge que así lo hubiera efectuado se constituía en orator, tal el título del solicitante de la dispensa, mientras que la otra parte era, desde entonces, la demandada, categorías del derecho que no se incluyen ni explicitan en la documentación que hemos recopilado, aunque resultan pertinentes para identificar a los actores conyugales ${ }^{14}$.

11 Marido y mujer podían demandarse por circunstancias concretas relativas a las obligaciones y derechos conyugales. Partida 3, tít. II, ley 5.

12 Gaspar Núñez, La Plata, 20.III.1603. Archivo y Biblioteca Nacionales de Bolivia (en adelante ABNB), EP Vol. 123, ff. 209-v.

13 Simón de Ledesma, La Plata, 22.II.1603. ABNB, EP Vol. 123, f. 201.

14 López Alarcón, 1963, D-112. 
En las fuentes utilizadas, las demandantes distaban de pertenecer a un mismo grupo social o étnico, adscripción que rara vez sometían a escrutinio aunque si lo expresaban, como Juana de Mecina, era para nombrarse "montañesa en hábito de india", toda una excepción en la densa pirámide poblacional urbana que marcaba un mestizaje y una opción de identidad visible tras la ropa pero que, en este caso, traslucía que un vasto colectivo femenino podía, desde las élites a los más variados grupos subalternos, presentar sus demandas de separación matrimonial. Consejeros, procuradores, abogados y escribanos eran atentos sostenedores de las demandas, siendo notable que 8 de las 21 mujeres que presentaron solicitud de separación protocolizaran el escrito ante el escribano Andrés González de Cavia, seguramente versado en el formato notarial, cuyo éxito frente a los tribunales corriera de boca en boca en la ciudad cabecera del sur andino.

Una vez resuelta favorablemente la demanda, la mujer que la había presentado adquiría un estatus civil excepcional. Apelando a la sentencia del juez eclesiástico, Ana Gómez, mujer del capitán Diego Velásquez de Salazar, se presentaba en 1595 como "separada y apartada" conforme al pleito de divorcio que trató contra su marido, tras el cual usaba de la licencia concedida por el corregidor del distrito para efectuar tratos y contratos ${ }^{15}$. De igual modo "apartada" por un lapso de diez años, se presentaba en 1608 Juana Montaño, esposa de Juanes Navarro, en virtud del pleito de divorcio que había seguido y por el cual, poder mediante a un procurador de causas, reclamaba la devolución de su dote, más los alquileres, casas, tiendas y demás bienes que había llevado al matrimonio ${ }^{16}$. Ocho años más tarde, en 1616, la misma Juana Montaño se identificaba como "mujer libre por estar divorciada por sentencia del juez eclesiástico de Juanes Navarro, mi marido" 17 .

Una presentación singular es la de doña María de Balmaceda, en este caso, la parte demandada conforme a derecho, en tanto protocoliza un otorgamiento de poderes a favor del procurador y de su hermano para que la representen ante el provisor del obispado de Charcas para que fenezcan el pleito de divorcio que le puso su marido, Mateo de Rastizábal, "sobre de si hubo fuerza en el casamiento que con ella contrajo" y sobre las demás causas y razones contenidas en su demanda, haciendo presentaciones, convocando testigos y efectuando probanzas, además de reclamar alimentos ${ }^{18}$. Se colaba aquí, como causal de la demanda y del problema de la convivencia, uno de los postulados tridentinos: el libre consentimiento de los contrayentes, que debía existir más allá de los tratos familiares que a menudo soslayaban los deseos de los convocados al vínculo. El hecho de desconocer la presentación de Mateo de Rastizábal y sus términos, el único cónyuge masculino que registramos efectuando una solicitud de divorcio, nos inhibe de ofrecer resultados sobre el pleito y los motivos extendidos de un marido, cuya voz al respecto de este caso no está en los protocolos.

Por su parte doña Mariana de Acevedo y doña Mariana de Loaysa recurren a sendos procuradores para que ante el excelentísimo señor arzobispo de Charcas y el gobernador y deán de la Catedral, y ante el provisor y vicario general pongan demanda de

15 Juan de Higueras. La Plata, 15-XII-1595. ABNB, EP Vol. 45a, ff. 162-163v.

16 Agustín de Herrera. La Plata, 6-V-1608. ABNB, EP Vol. 101, ff. 172-172v.

17 Alonso Fernández Michel. La Plata, 4-III-1616. ABNB, EP Vol. 82, f. 165.

18 Andrés González de Cavia. La Plata, 13-III-1614. ABNB, EP Vol. 69, ff. 241-241v. 
nulidad del matrimonio que habían contraído con Juan García Alejandro y Bartolomé González, respectivamente, por las causas y razones que con ellos tienen comunicado $^{19}$. La nulidad, tan compleja de solicitar como de conseguir y que podía obedecer a la bigamia de uno de los cónyuges, a la violencia para obtener el consentimiento matrimonial, a la imposibilidad de consumar el débito conyugal, a la existencia de consanguinidad o afinidad entre los casados, por error en la categoría de la persona o por defectos de forma canónica, resaltaba la humana imperfección de una unión que, conforme al derecho y al decreto Tametsi de 1563, se catalogaba como perfecta e indisoluble ${ }^{20}$. No alcanzamos a detectar los motivos por los cuales doña Mariana de Acevedo y doña Marina de Loaysa solicitaban la nulidad de sus matrimonios.

Como han señalado los investigadores de la materia, la violencia y los malos tratos constituyeron las faltas más reiteradas para que las mujeres incoaran sus divorcios. Así, doña Luciana de Ybarra, mujer legítima del Licenciado Hernando de Olivares, decía llevar pleito de divorcio con su marido "en razón de los tratamientos que le ha hecho", demanda que estaba en manos del arzobispo de La Plata y a punto de obtener sentencia. Doña Luciana se quejaba de que su marido le había "echado muchas personas y rogadores para que vuelva a hacer vida con él, que promete que la tratará muy bien". Más allá de su convicción de que el divorcio era la mejor instancia para evitar la violencia y los malos tratos, doña Luciana se condolía por verse sola y pobre y no teniendo con que sustentarse ni con qué medios seguir el pleito, en virtud de cuyos apremios "ha venido en que vuelva a hacer vida maridable con el dicho Licenciado Hernando de Olivares, mi marido, y esto lo hago contra mi voluntad y por las causas referidas" dejando constancia de que si volviera a hacer vida maridable to ha sido forzada y apremiada de la necesidad que tiene por no tener que comer ${ }^{21}$. Más allá de esta decisión de retornar a la convivencia debido a su indigencia, doña Mariana dejaba en vigor los poderes otorgados para proseguir el pleito de divorcio cuando otras condiciones se lo permitieran.

Hasta aquí ejemplos de las presentaciones formales en el ámbito secular, el esclarecimiento del estatus o identificación de las divorciadas como apartadas, separadas o libres, y el ejercicio de sus derechos como tales aunque dependiendo de un apoderado especialmente nombrado o del mismo marido para poder sobrevivir.

Dentro del mismo ámbito, el secular, donde las causas reales de un divorcio parecían esquivas, surge una voz que intimida por su franqueza y sorprende por la frontal sinceridad con que plantea su demanda, soslayando los prejuicios y estereotipos de clase, estatus y género que una mujer de su condición pudiera trascender y lesionar al confrontar a su marido y embarcar a su familia tras una causa que estimaba justa y necesaria para reparar su honor y recuperar su mellada autoestima. A comienzos de Enero de 1605 parecía, desde su auto confinamiento en el Monasterio de los Remedios de la ciudad de La Plata, doña Ana de Córdoba y Cabrera solicitando la nulidad de su matrimonio y justificando su presentación en que,

\footnotetext{
19 Andrés González de Cavia. La Plata, 30-VII-1611. ABNB, EP Vol. 68, ff. 819v-820; Ibídem. La Plata, 13-IX-1611, ff. 882-883.

20 GHIRARDi, 2004, pp. 234-309.

21 Juan de Loarte. La Plata, 11-IV-1611. ABNB, EP Vol. 140, ff. 109-v; Ibídem. La Plata, 25-V-1612. ABNB, Vol. 141 f. $202 \mathrm{v}$.
} 
antes de que yo me casara con Juan Porcel de Padilla, el susodicho había tenido amistad y cópula carnal con doña Juana de Cabrera, mi hermana legítima, hija de Hernán Cabrera de Córdoba y de doña Isabel Velásquez de Yebra, mis señores padres, difuntos, y calando lo susodicho, el dicho Juan Porcel pidió a la dicha doña Isabel de Yebra, mi madre, me casara con él, como lo hizo, estando como estábamos ignorantes del trato y comunicación carnal que tenía y había tenido con la dicha mi hermana, de que resulto que desde el mismo día, punto y hora que conmigo se caso ha tenido conmigo grandes disgustos y pesadumbres, tratándome no como a su mujer y obligándome por sus malos tratamientos a entrarme en este Monasterio de Monjas de Nuestra Señora de los Remedios, donde estoy reclusa reclusa (sic) por huir de los malos tratamientos que me hacía y con estar en el dicho recogimiento: es tanto el odio que el dicho Juan Porcel me tiene que por me hacer daño va consumiendo toda la hacienda que tenemos, así la que conmigo hubo en dote y casamiento como la que hubimos y adquirimos en el tiempo de nuestro matrimonio. Y porque habiendo habido dicho impedimento, yo pretendo alegar de nulidad y pedir lo que más me convenga para que se dé por ninguno. Y las personas que saben de lo susodicho están en la villa de Potosí, y para que declaren lo que acerca de ello saben y vieron me conviene dar poder a persona que en mi nombre lo haga, otorgo y conozco por esta presente carta que doy y otorgo todo mi poder cumplido y bastante tal cual de derecho se requiere y más puede y debe valer a don Pedro de Cabrera y Córdoba, mi hermano, y a Pedro Díaz Téllez, escribano, a ambos a dos juntamente y a cada uno y a cualquiera de ellos por si insolidum con facultad que lo que el uno comenzare lo pueda fenecer y acabar el otro para que por mí y en mi nombre y como yo misma puedan parecer ante cualesquier jueces y justicias eclesiásticas y en la dicha razón hacer los pedimentos requerimientos, citaciones, protestaciones que convengan presentar escritos, testigos y probanzas y pedir que se examinen de mi pedimento o de oficio como a mi derecho y justicia mejor este y hagan todas las diligencias judiciales y extrajudiciales que sean necesarias y que yo haría y podría hacer estando presente, que el poder que para ello se requiere ese mismo les doy con sus incidencias y dependencias libre y general administración ${ }^{22}$.

Sin duda, la causal tenía fundamento suficiente como para justificar no sólo la presentación sino la nulidad del matrimonio en tanto aunaba el adulterio a los malos tratamientos, los dos motivos graves que ameritaban la solicitud de divorcio. El adulterio del marido, a más de haber tenido estado público y derivar, por ende, en la solicitud de su esposa, no había significado el engaño con cualquier mujer sino con su cuñada, la hermana de su esposa, con quien mantenía relaciones antes de casarse con la demandante. Pero lo que era aún más detonante era que doña Juana de Cabrera, la amante, lo cual no explicita la demanda, también era mujer casada ${ }^{23}$. Es factible que

22 Philippe de Godoy. La Plata, 16-I-1605. ABNB EP Vol. 65, ff. 5v-6v. CostA, 2008, pp. 6-7.

23 Doña Juana de Cabrera estaba casada con quien fuera tesorero $y$, hasta su muerte, alguacil mayor del Cuzco, el comerciante extremeño Cristóbal de Espinoza Villasante, con quien no había engendrado hijos. La manifiesta y confesa devoción de Espinoza Villasante por su mujer quedó plasmada en las generosas mandas testamentarias con que la favoreció, más allá de los incidentes descriptos, Gaspar Núñez. La Plata, 23-III1607. ABNB, EP Vol. 125, ff. 503-511v; Ibídem. La Plata, 6-VIII-1607, ff. 513-515v; 518-526. La crueldad junto al abuso físico y, sobre todo el adulterio, acto violatorio de los votos matrimoniales, eran causal indiscutible de divorcio. La publicidad del adulterio lo hacía punible, aunque si ese comportamiento deviniera en una conducta socialmente escandalosa, la denuncia del caso acreditaba mayor fortaleza. Cuatro causas hacían a un varón casado culpable de adulterio y pasible de tomar su conducta como antesala del divorcio: si lo había 
frente a la existencia de la publicidad y de testigos de semejante doble afrenta al matrimonio y oprobio a la familia Cabrera de Córdoba, Porcel de Padilla ni siquiera hubiera comparecido ante el tribunal, dejando que la demanda procediera en rebeldía ${ }^{24}$.

Esta situación lesionaba la reputación de una de las familias prominentes de $\mathrm{La}$ Plata. El padre de doña Ana, Hernán Cabrera de Córdoba, había sido encomendero de la jurisdicción y se había casado con una castellana emparentada con los Paniagua de Loaysa, riquísimos feudatarios, funcionarios y empresarios coloniales cuya red relacional trascendía el espacio local, alcanzaba el virreinal y mantenía estrechos lazos transatlánticos con la Extremadura natal y la corte de Madrid, donde residían parientes y funcionarios ${ }^{25}$. Más allá de que el extremeño don Gabriel Paniagua de Loaysa era uno de los cuatro "dones" entre la treintena de encomenderos de La Plata y caballero de Calatrava, había servido como corregidor del Cuzco y amasado una enorme fortuna. Sus transacciones comerciales y sus vínculos con la burocracia virreinal lo relacionaban con los hermanos Porcel de Padilla y Porcel de Peralta, conocidos comerciantes de Charcas, mientras que dos de sus yernos eran reputados oidores y uno de ellos devino en funcionario del Consejo de Indias, me refiero a los Licenciados don Francisco de Alfaro y Juan de Solórzano Pereyra ${ }^{26}$. De manera que toda una red relacional, en este excepcional caso de adulterio, maltrato y solicitud de divorcio de una mujer de la más alta jerarquía social, conocía y era silente sostén de los desgraciados eventos del matrimonio y el confinamiento de doña Ana, cuyos consejeros a la hora de la presentación de la demanda de nulidad y divorcio estaban seguramente dentro de su familia extensa, atendiendo su caso dentro y fuera del Monasterio de los Remedios de La Plata desde donde la solicitante hablaba, peticionaba, gestionaba y administraba, además de firmar de puño y letra cada una de sus solicitudes y protocolos que la involucraran ${ }^{27}$. Fue en el espacio de depósito donde doña Ana, y como ella otras mujeres que solicitaban su divorcio, halló la visibilidad pública y la credibilidad social que trascendía las desigualdades de género al permitírsele hablar y exhibir la aguda conciencia de que su reputación dependía de la sanción pública, ya que lo público y notorio poseían enorme valor en la sociedad colonia ${ }^{28}$.

Como mujer maltratada y a la que además se le había cometido adulterio público con una hermana, asistían a doña Ana sobradas razones para abandonar el hogar conyugal y recluirse en una institución religiosa recurriendo, tal como lo hizo, al vicario general para dar cuenta de la situación y legalizar la separación. El depósito,

cometido con una mujer casada, si lo había practicado en su hogar con el ama de leche de sus hijos o con una mujer de su servicio o si el acto era conocido y abiertamente sostenido como para generar escándalo público. La primera y la última causa aplicaban a la conducta adúltera de Juan Porcel de Padilla. Cf. ArROM, 1985, pp. 64-65, 208-209.

24 Nizza Da Silva, 1991, p. 344.

25 PRESTA, 2000b, pp. 247-248.

26 Alonso Fernández Michel. La Plata, 10-X-1603. ABNB EP Vol. 72, ff. 981-989; Ibídem. La Plata, 26XII-1613, ff. 1433-1437; Presta, 2000a, pp. 132-136.

27 El Monasterio de Monjas de los Remedios de Santa Mónica de la ciudad de La Plata había sido proyectado por los encomenderos de la jurisdicción, bajo la protección espiritual de los religiosos de San Agustín, en 1567. Se proponía albergar a las hijas de la élite que demostraran vocación religiosa o a las que sus familias no estaban en condiciones de casar, CALANCHA, [1639] 1976, II, p. 1178. La construcción y acta fundacional ocurrió en 1574, GARCIA QuinTANILLA, 1963, III, pp.145-149.

28 VAN DEUSEN, 2007, p. 150. 
como real instituto, era la opción más virtuosa para evitar los malos tratamientos y la continuada violencia de Porcel de Padilla. Como tal, el depósito confería tutela y seguridad a la mujer tras la figura de un tercero o, en este caso, de una institución, siendo automático en caso de separación, ya que no era conveniente que los esposos cohabitaran mientras pleiteaban. De allí en más, sigue la obligación alimentaria en favor de la víctima, por ello la insistencia de doña Ana por recibir cuotas que le permitieran vivir acorde a su estatus ${ }^{29}$.

Iniciado el proceso, y en sucesivas presentaciones, doña Ana de Córdoba y Cabrera, requería los resarcimientos económicos del caso. A meses de la demanda, doña Ana se decía "apartada" de su marido mientras continuaba viviendo en Los Remedios. Allí, a más de otorgar poderes a su presbítero y a un procurador de causas, reclamaba la cobranza de todo lo que se le debiera y, sobre todo, los alimentos que estaba obligado a darle su marido, Juan Porcel de Padilla, a quien solicitaba reiteradamente la devolución de su cuantiosa dote, arras y gananciales ${ }^{30}$. A propósito del marido, vecino de La Plata, comerciante y con intereses en la minería de Potosí y otros asientos aledaños, había sido beneficiado por dos herencias de notables residentes en la ciudad, la del ex funcionario Diego Bravo y la de quien fuera fundador y gobernador de Tarija (hoy capital del Departamento homónimo del sur boliviano), Luis de Fuentes y Vargas, quien instantes previos a su muerte cambió su testamento a favor de Porcel de Padilla, en cuya casa falleció ${ }^{31}$.

A mediados de 1607, el pleito de divorcio estaba en estado de apelación en Los Reyes, para lo cual doña Ana daba su poder a don Antonio Manrique, fiscal del Santo Oficio de la ciudad de Lima para continuarlo ${ }^{32}$. Al mismo apoderado mandaba, dos años después, que cobrara todos los maravedíes y bienes que le debieran por escrituras en cualquier parte del Perú, en Tierra Firme y en España, para que donde estuvieran radicados se embargase todo lo perteneciente a Juan Porcel de Padilla, quien aún conservaba la dote de 40 mil pesos ensayados más las arras nupciales, los que le estaban mandados devolver a por la sentencia que el deán y Cabildo catedralicio de La Plata habían librado en su favor, la cual había sido confirmada por el juez metropolitano de la ciudad de Los Reyes, quienes también trabaron en Porcel un embargo por mil pesos ensayados para proveer alimentos a su esposa ${ }^{33}$. De manera que a los cuatro años de presentada la primera demanda, doña Ana de Córdoba y Cabrera obtenía la sentencia de separación. Por lo que toca a la nulidad, no tengo indicios de que le hubiera sido concedida. Sin embargo, y salvo para condicionar el devenir económico de los bienes comunes, la voz de Juan Porcel de Padilla ni siquiera es un susurro en

29 Nizza da Silva, 1991, p. 341; Arroyo Vozmediano, 2008, pp. 132-141; Langue, 2005, p. 7, 11; GáLvez Ruiz, 2006, pp. 76-77. VAN Deusen, 2007, pp. 107-138. Costa, 2007, pp. 6-7, advierte que el depósito es nombrado en la documentación con que trabajó como "secuestro o reclusión", términos que estima deben matizarse. Si de "secuestro" se tratara, el mismo no restringía la libertad femenina sino que garantizaba mayor independencia del marido y libertad de movimiento. Según la autora, en Cataluña, el depósito transcurría, generalmente, en casas de familiares o amigos, pocas veces en establecimientos caritativos o carcelarios.

30 Pablo López. La Plata, 8-VIII-1606. ABNB, EP Vol. 65, 2 ff. s/f.

31 Alonso Fernández Michel. La Plata, 18-V-605. ABNB, EP Vol. 74, ff. 443-445v; Gaspar Núñez. La Plata, 10-VIII-1598. ABNB EP Vol. 119, ff. 175-183v.

32 Pablo López. La Plata, 1-VI-1607. ABNB EP Vol. 65, s/f.

33 Philippe de Godoy. La Plata, 12-VII-1609. ABNB EP Vol. 62, 4 ff. s/f. 
este inusual proceso de divorcio por adulterio y maltrato que sufriera una esposa del más elevado rango social en La Plata ${ }^{34}$.

En 1612, doña Ana, apartada de su matrimonio, como las mujeres de su misma condición, hallaba dificultades para insertarse en una sociedad que la había autorizado a no hacer vida maridable aunque sujeta al matrimonio; estaba sola sin ser viuda, había sido doncella y procreado hijos cuando casada, pero al separarse ni siquiera era libre como una soltera para efectuar vida pública por carecer de un estatus socialmente aceptable. Si bien la justicia eclesiástica había fallado en favor de doña Ana, la sociedad no podía permitirse integrar a quien, más allá de las humillantes y justificadas razones de su demanda, había desafiado el orden establecido. Si bien el divorcio amparaba los reclamos de las mujeres a quienes el matrimonio sometía a oprobiosas condiciones de vida, la separación concedida no erradicaba el vínculo indisoluble del matrimonio, sino que les evitaba la convivencia, la cohabitación con maridos violentos y descarados. Por ello habrá de notarse que las divorciadas, aunque amparadas por la ley para evadirse de un vínculo pernicioso, permanecían en el limbo social colonial del no lugar una vez separadas de sus maridos. Quizás por ello doña Ana tomaba la decisión de partir a los reinos de España. El periplo iba a realizarlo junto a su hermana doña Francisca y su esposo, don Francisco Porcel de Peralta, su cuñado y hermano de su esposo, y uno de sus hijos, a quien proponía dar estudio, para lo cual solicitaba la correspondiente licencia a Juan Porcel de Padilla, quien por siempre sería su marido y a quien debía sumisión y obediencia ${ }^{35}$. Tras la licencia, se da traslado de la sentencia de divorcio y separación del matrimonio quoad thorum et mutuam coabitationem que uniera a doña Ana de Córdoba y Cabrera y a Juan Porcel de Padilla según los autos del 26 de marzo y 28 de abril de 1612, por los cuales se confirmaba el dictamen del doctor don Juan Velásquez, arcediano de la Catedral de Los Reyes, juez metropolitano de ese obispado, que confirmaba la previa del deán y Cabildo de La Plata. En ella se establecía que doña Ana no estaba obligada a vivir en el Monasterio de los Remedios y se condenaba a Juan Porcel de Padilla a que dentro de los diez días de la notificación de la sentencia le devolviera los 40 mil pesos ensayados de su dote, arras y su multiplico ${ }^{36}$. De resultas de la sentencia y sus mandatos y del deseo de doña Ana de partir a la península, se concertaba con Juan Porcel de Padilla en recibir 26.000 pesos ensayados, 14.000 de ellos que en Potosí había entregado a un particular para que los invirtiera en los reinos de España y en los estados

\footnotetext{
34 Nizza DA SiLva, 1991, p. 353, caracteriza al adulterio como "la causa mayor del maltrato".

35 Alonso Fernández Michel. La Plata, 13-IX-1612. ABNB EP Vol. 79, f. 388.

36 Ibídem, fs. 389-390. A fines comparativos nótese que, por entonces, una botija de aceite costaba 9 pesos corrientes, una libra de pimienta 4 pesos, la libra de canela 14 pesos, una libra de jabón 1 peso, una espada 12 pesos, un calderón 5 pesos, una botija de vino tinto 25 pesos, una vara de terciopelo 14 pesos, la vara de tafeta de México 3 pesos y medio, la de la China 2 pesos y 2 reales, una vara de ruan peso y medio, la vara of cañamazo 1 peso. Asimismo, el peso corriente, moneda en que se efectuaban las transacciones ordinarias, equivalía a 8 reales o 272 maravedíes, siendo que cada real contaba 34 maravedíes, mientras que el peso ensayado, en el cual se enteraban los tributos, equivalía a 450 maravedíes de 12 reales y medio por unidad. Una buena casa de morada en La Plata podía costar entre 3.000 y 7.000 pesos ensayados y con sus muebles y tapicería más de 10.000 , lo cual denota lo abultado de la dote que llevó al matrimonio doña Ana de Córdoba y Cabrera. Andrés González Cavia. La Plata, 17-III-1609. ABNB, EP Vol. 68, ff. 526-529v; Juan Bravo. La Plata, 24-XI-1570. ABNB, EP Vol. 23, ff. 469-471; Ibídem. 18-X-1570, ff. 460-461; Presta, 2010.
} 
de Italia y Milán -según una instrucción y memoria oportunamente otorgada- cuyo cobro debía gestionar doña Ana. Además le daría cada año y por cuatro consecutivos 3.500 pesos desde la fecha de la escritura de concierto más los intereses de los 14.000 a razón de 20.000 el millar, descontado el principal que se fuera pagando. Adicionalmente, le confería a doña Ana el poder para cobrar otros 10.000 ensayados que tenía en los reinos de España en poder del Dr. Gregorio López de Madera, del Consejo de Su Majestad, cuyos recaudos para su cobranza se comprometía a entregar, descontando los costos y averías que pudieran haberse causado al momento que los recibió López de Madera. Adicionaba Porcel de Padilla otros 2.000 pesos pagaderos a fines de diciembre de 1612 para el viaje y camino de su mujer y para armar y poner su casa en Granada, ciudad natal de los Porcel, autorizando a su hijo don Juan a viajar con su madre y $\operatorname{criados}^{37}$.

La devolución de la dote era una instancia laberíntica, en la que el marido, amparado por el patriarcado, los derechos matrimoniales y su posición de género, conservaba los indisolubles derechos de administración del patrimonio común y dotal, mientras que el divorcio le había cercenado el derecho al cuerpo de su mujer y a la mala vida conyugal que se había empeñado en tener. Doña Ana, nacida y criada en La Plata, iba a radicarse en la patria chica de su esposo y, desde allí, supervisada y controlada, debería contratar gestores y apoderados para dar con los retazos de su dote esparcidos por Madrid, Milán y quién sabe en qué otras plazas de Italia. Pero eso no era todo. El divorciado no perdía ocasión para limitar la frágil independencia de la madre de sus hijos. Con tantas idas y vueltas, recomendaciones y subterfugios, Porcel de Padilla buscaba retardar la devolución de una dote que no tenía y, a la vez, proteger los montos que de ella enviara a distintas plazas mediterráneas advirtiendo que si muriera su hermano y apoderado, doña Ana debía depender del Dr. López de Madera y su consejo, sin poder enajenar las rentas por efecto alguno sin licencia de su parte y expresa voluntad, con lo cual el divorcio y sus consecuencias económicas parecían no operar en los tratos y contratos de quien siendo dueña de su dote, arras y gananciales, luego de la sentencia favorable de separación, no podía acceder a ellas. Más aún, si doña Ana muriera en España, Porcel de Padilla dejaba en claro que la dote y demás bienes concesionados volverían a él, como padre de los hijos de ambos, a más de las rentas y fondos devueltos. Y para sellar la dependencia de género y la injerencia de un marido que físicamente no lo era pero podía legalmente actuar como tal, doña Ana aceptaba las condiciones impuestas, perdonaba a Juan Porcel de Padilla y desistía de los derechos sobre su dote, cediéndolos a favor de sus herederos, comprometiéndose a no revocar, limitar ni contradecir en muerte o vida, por testamento o fuera del, lo que en esa escritura había consensuado ${ }^{38}$.

Divorciada o separada, apartada o libre, a una mujer como doña Ana -a quien el divorcio eclesiástico había autorizado a evitar la convivencia y soslayar las obligaciones conyugales sin anular el vínculo- lo que resultaba imposible de sortear era a su omnipresente marido, que carecía de inhibiciones y limitaciones para administrar sus legítimos bienes, como la dote, o supervisar decisiones de vida, sobre dónde y

\footnotetext{
37 Alonso Fernández Michel. La Plata, 13-IX-1612. ABNB, EP Vol. 79, ff. 391v-397.

38 Ibídem, ff. 399-401.
} 
cómo vivir. El Derecho canónico había ponderado las faltas graves al matrimonio de Porcel de Padilla para conceder el divorcio. Sin embargo, consumada la sentencia de separación, se imponía "el peso de lo patriarcal", que volvía a resaltar la minoridad femenina y a opacar la libertad consagrada por el apartamiento del vínculo ${ }^{39}$. Aunque el matrimonio se hubiera roto, el marido continuaba gobernando la vida y el patrimonio de quien fuera su mujer, ejerciendo autoridad, poder de administración y supervisión de toda determinación o deseo de quien estaba legítimamente apartado.

Años más tarde, otro caso de solicitud de divorcio por la parte femenina también daba cuenta del adulterio y maltrato de un esposo que, por circunstancias fortuitas relacionadas con su amancebamiento, lograría la desestimación de la demanda puesta por su mujer. En un expediente notable, en el que se oyen múltiples voces, datado en diciembre de 1634, ubicado en el Archivo Arquidiocesano de Sucre, repositorio que concentra los papeles de los conventos, iglesias y monasterios coloniales y las presentaciones de los particulares ante la justicia eclesiástica, aparece en inicial contrapunto la palabra de los esposos doña Ángela Fernández de Castro y Diego González Romero. Doña Ángela, a través de su procurador, demandaba a su marido, con quien decía haberse casado "forzada y contra su voluntad". Esta manifestación contravenía los principios tridentinos que, si bien no estipulaban la igualdad de los convocados al vínculo al sostener la inferioridad de la mujer, reconocía sus derechos a los gananciales y a la dote y postulaba el mutuo consentimiento de quienes iban a contraer matrimonio, más allá de los acuerdos familiares previos que los futuros cónyuges debían refrendar. Pero más allá de la falta de consentimiento, doña Ángela acusaba a su marido de violencia y malos tratos, aduciendo que

la ha tratado con contrita sevicia, crueldad y aspereza, de hecho y de palabra, y una y muchas veces le ha puesto las manos aponiendola ( $\mathrm{sic}$ ) como si fuera su esclava y no tratándola con la afición manual que los sagrados cánones y santos concilios mandan y disponen, cuyo motivo ha tenido el susodicho por estar como esta amancebado con una india en quien tiene cuatro hijos, cometiendo adulterio a la dicha mi parte la cual, aunque por medio de religión y personas graves y cristianas ha procurado aquietar al dicho Diego Romero, su marido y reducirlo a la concordia, paz y quietud que el estado matrimonial requiere ${ }^{40}$.

En virtud de la "rebeldía" de Diego Romero, quien según la demandante perseveraba en el adulterio, la ofensa mayor al matrimonio, la esposa solicitaba el divorcio, la restitución de su dote de 10.000 pesos y el embargo de los bienes del marido a fin de recuperar los propios. Y es aquí cuando la voz del marido se hace audible y contundente, a diferencia de otros casos, justificando la falta de vida maridable en las prácticas autoritarias de una suegra que le impedía ver y cohabitar con su esposa.

Diego González Romero digo que yo contraje matrimonio según orden de la Santa Madre Iglesia con doña Ángela de Castro habrá un tiempo de diez meses, la cual está

39 Cf. Fernández, 2013, p. 188.

40 Doña Ángela Fernández de Castro contra Diego Romero, su marido. Archivo Arquidiocesano Monseñor Taborga de Sucre (en adelante ABAS), Divorcios 1, ff. 1-1v. Resaltado de la autora. 
en casa de Isabel de Valencia, su madre, que con mano poderosa y sin ocasión alguna la tiene en su poder, supeditándola y persuadiéndola a que no haga vida maridable conmigo, cual es su obligación, para lo cual me impiden la entrada en su casa, cerrándome la puerta y dando orden a la gente de su servicio a que no me dejen entrar a ver a la dicha mi mujer y para que yo libremente pueda habitar con ella y servir a Dios en el estado del matrimonio ${ }^{41}$.

Acto seguido, González Romero solicitaba mandamiento para que "me entreguen a mi mujer", pidiendo penas y agravantes a quien lo impidiera. Sin embargo, un miembro del Arzobispado de La Plata, el racionero, provisor y vicario general, Dr. Bartolomé de Cervantes, visto los autos de la presentación, mandó a doña Ángela Fernández de Castro a vivir en depósito en casa de un vecino honorable sin poder abandonar su estancia salvo para "oír misa y frecuentar los santos sacramentos", lo que rápidamente contradijo el clérigo Balthasar de Ávila, oficial mayor del arzobispado en la causa de divorcio y separación, quien denegó el pedido de doña Ángela y le mandó cohabitar y hacer vida maridable con su marido, juzgando las causas alegadas insuficientes, "ni legítimas ni bastantes... fingidas e inventadas sólo a fin de verse libre ni obligada a la obediencia y sujeción que ha de tener su marido". Reafirmando las desigualdades entre los cónyuges y reiterando la potestad de la docencia y la ejemplaridad debidas al marido, más allá de los métodos, Ávila estimaba que si el enojo de doña Ángela obedecía a "alguna corrección fraterna" (eufemismo que suavizaba el maltrato o el castigo corporal) ello no era causa legítima para divorcio y falta de cohabitación, pues "el marido, como cabeza, que tiene dominio de su mujer, puede muy bien usar de un leve castigo cuando ve que tiene necesidad del su mujer para su corrección" 42 . Sólo una cabeza aunque dos cuerpos eran requisito válido para formalizar el vínculo, de manera tal que el cura hacía caso omiso del amancebamiento de Romero con una india en tanto, como dueño de la cabeza, lo juzgaba sin más como "buen cristiano, temeroso de Dios e incapaz de tal ofensa", obedeciendo el pedido de divorcio de doña Ángela a complacer y agradar a su madre, quien aborrecía y malquería "de muerte" a Romero, dando por nula la demanda de separación, ignorando todas las causales de la demanda $^{43}$. Va de suyo que el patriarcalismo institucionalizado que encarnaba el argumento del clérigo Ávila fue contestado por la parte demandante, que recibió como respuesta el cese de la causa que movía su presentación, ya que la india con quien Romero "había tenido algunos holgos", sin haber estado "amancebado y mal amistado", había fallecido, con lo cual doña Ángela no tenía motivo alguno para eludir la vida maridable que le imponía el sagrado matrimonio ${ }^{44}$. La exhibición del Libro de Difuntos de la Catedral de La Plata, consignando el fallecimiento de una tal María Beatriz

41 Ibídem, f. 6.

42 Cabía al marido el poder de corrección, pudiendo castigar a su mujer con moderación y afecto. Ello, más allá de consagrar la minoridad femenina, hallaba su justificación en el Nuevo Testamento. En las Instrucciones para cada estado, 22-24, de la Epístola de San Pablo a los Efesios se lee, "Las casadas estén sujetas a sus maridos, como al Señor. Porque el marido es cabeza de la mujer, así como Cristo es cabeza de la Iglesia, que es su cuerpo, del cual él mismo es salvador. De donde, así como la Iglesia está sujeta a Cristo, así las mujeres lo han de estar a sus maridos en todo".

43 Doña Ángela Fernández de Castro contra Diego Romero, su marido. ABAS, Divorcios 1, ff. 14-15v.

44 Ibídem, f. 25. Resaltado de la autora. 
india el 5 de Junio de 1635 ponía punto final al adulterio, al amancebamiento, los malos tratos y la sevicia de Diego González Romero, quien recuperaba a su mujer y las obligaciones maritales debidas, quedando a salvo de la demanda de divorcio y en libertad para corregir, gobernar y conducir el destino de su esposa y del matrimonio.

Por último, una presentación escueta pero excepcional, procedente del espacio rural, tan ausente de los expedientes mayormente construidos en las ciudades cabeceras españolas del territorio colonial, da cuenta del mal habido matrimonio entre el carpintero Pedro Ramírez de Toledo, natural de Ávila, habitante del valle de Pitantora (hoy Provincia de Chayanta, Departamento de Potosí), quien en 1593 decía haberse casado hacía más de doce años con María Ruiz, con quien había tenido muchas pesadumbres, "por ser ella soberbia y yo mal acondicionado", motivos por los que María había solicitado el divorcio y el vicario accedido a depositarla, evento que lo cegó de cólera y desasosiego. Este aparentemente simple caso de demanda de divorcio suscitado entre una pareja de pobres trabajadores rurales mal avenidos llegó a oídos de funcionarios de la Inquisición, porque en tanto abrumado y desolado por la situación, el carpintero hizo público que, a su juicio, "era un hereje el hombre que se casaba para tantas desventuras" ${ }^{45}$. La sola mención de la herejía y la subsiguiente ofensa a Dios, motivó que los testigos derivaran sus declaraciones ante los funcionarios del Santo Oficio, ávidos de escuchar blasfemias de reos que frente a situaciones personales adversas exclamaran en público sus iras contra la Fe y el descrédito del sacramento del matrimonio ${ }^{46}$. Así, Ramírez de Toledo fue acusado por testigos de haber dicho que "votaba a Dios que todos los que estaban casados en esta tierra estaban condenados al infierno y que ninguno se podía salvar, ni los solteros tampoco"47. Un segundo testigo afirmó que el verborrágico marido había dicho que "los hombres que se casaban no eran cristianos sino herejes y que mejor es estar los hombres amancebados que no casados porque el amancebado no ofende tanto a Dios como el casado"48. Lo que sigue da cuenta de las desventuras de un hablador, blasfemo, impaciente e irascible artesano que por el pleito de divorcio que le puso su mujer y su desmesurada respuesta pública debió abjurar de Levi y sufrir el destierro del valle en que habitaba, sin dársele más pena por ser muy pobre y tener muchos hijos que alimentar. El expediente no da pistas de la prosecución de la causa del divorcio.

\footnotetext{
45 Relación de causas que se han despachado en la inquisición del Perú fuera del auto público de la fe desde prim. de Abril del año pasado de 1600 hasta fin de Marzo de este prte. año de 1601. Archivo Histórico Nacional. Madrid. (en adelante AHN), Inquisición, Libro 1029, ff. 108-109v.

46 La blasfemia, dirigida directamente a Dios o indirectamente a él a través de insultos a los santos, recibía penas severísimas impuestas bien por el derecho civil o el canónico. Si el blasfemo era un laico podía quedar excomulgado y, dependiendo de la gravedad de su imprecación, podía recibir una multa, azotes, sometimiento a ayuno, negación de sepultura, mutilación de la lengua, cárcel o la muerte. Véase, CASTAÑEDA DELGADO Hernández APARICIO, 1989, pp. 280-293; Millar, 1997, pp. 274-290

47 Relación de causas que se han despachado en la inquisición del Perú fuera del auto público de la fe desde prim. de Abril del año pasado de 1600 hasta fin de Marzo de este prte. año de 1601. AHN, Inquisición, Libro 1029, f. 108v.

48 Ibídem, f. 109.
} 


\section{CONCLUSIONES}

Trento y su decreto Tametsi habían regulado y consagrado el ritual, la publicidad, la indisolubilidad y el libre consentimiento matrimonial convertido en sacramento. En la letra se pautaba el consenso entre las partes; en la práctica, tal variable había quedado entre suspendida, congelada o soslayada por la costumbre, en tanto persistía el arreglo familiar matrimonial sin la intervención o con escasa participación de los contrayentes ${ }^{49}$.

Las escuetas voces que aparecen en las presentaciones seculares de separación y nulidad pintan un universo variado de mujeres que, acodadas en los distintos y múltiples peldaños de la escalera social, presentan descripciones similares sobre el maltrato masculino abrigando la esperanza de librarse de una atadura amparada en la ley divina que sólo garantizaba su infelicidad.

El desenvolvimiento del divorcio de doña Ana de Córdoba y Cabrera, los detalles de su estrategia de viaje para sobrevivir fuera de La Plata, el regateo mezquino de su dote, situación en la que su marido se erigía como el astuto comerciante que era, patentizaba el miserable devenir de su vida y permite evaluar que la separada, aunque integrante de la élite, carecía de libertad para administrar su propia vida, disponer de su patrimonio o tomar decisiones acerca del lugar en que buscaba radicarse o cómo y con quien vivir. Aunque no sujeta a la vida maridable, su matrimonio continuaba vigente al tener que depender del consentimiento de su marido para conducir su misma existencia y la de sus hijos.

Doña Ángela Fernández de Castro toleró el adulterio y los malos tratos de un marido que se vio favorecido por la resolución de un fiel ministro de la cultura patriarcal, que había institucionalizado y naturalizado las desigualdades dentro del matrimonio. Assí, el vicario Ávila sostuvo las obligaciones de la mujer en el matrimonio más allá de cualquier ofensa física y moral recibida y desestimó el adulterio y la paternidad masculina fuera del vínculo como causal de divorcio. Había entendido que el amancebamiento con procreación daban cuenta solamente de "algunos holgos", que de modo alguno lesionaban el matrimonio. Además, muerta la india María Beatriz, con quien Diego González Romero tenía relaciones fuera del matrimonio, no existían excusas para que la legítima esposa reiniciara la vida maridable y archivara su demanda de divorcio.

Por su parte, el carpintero abulense Pedro Ramírez de Toledo es una voz masculina que se escucha en las presentaciones de divorcio, aunque su fama y notoriedad surgen de la desesperanza por el depósito que de su mujer había hecho el vicario platense al apartarla del hogar y de un matrimonio mal habido por más de una década. Sus ofensas a Dios, fruto de su naturaleza iracunda, distaron de convencimiento o cabal ponderación del acto de blasfemar a la divinidad, lo cual fue comprendido por la autoridad que lo desterró de su hogar sin imponer multa u otro castigo en virtud de su pobreza. El matrimonio, en este caso, derivó en una presentación inquisitorial por la locuacidad e imprudencia de un cónyuge exasperado y sobrepasado emocionalmente por la demanda de divorcio que le había puesto su mujer.

\footnotetext{
49 Una síntesis de las prescripciones tridentinas en LATASA, 2005, p. 238.
} 
A pesar de que el divorcio fue una opción extrema y no deseada porque laceraba el sacramento matrimonial, su sentencia favorable tan solo liberó a las esposas de la presencia física, la tortura moral y el oprobio del maltrato y el adulterio de sus maridos. De modo alguno parece haber significado la antesala de una vida libre y autónoma, quizás de una más calma, sin insultos, correctivos infames e insoportable convivencia.

Si bien el matrimonio constituyó un mandato cultural y social que no conoció prácticas diferenciales de clase, etnicidad o género en la colonia, sus iniquidades y falencias abrazaron a hombres y mujeres por igual y a todo nivel social. Las mayorías femeninas que demandan la separación permiten, por sobre todas las opiniones vertidas, atisbar cierto pragmatismo con que los varones abordaron el matrimonio. Al estar amparados por las prácticas culturales y las instituciones contenidas en el habitus, que infantilizaron a las mujeres, avalaron la dominación masculina, naturalizaron los malos tratos y permitieron la violencia doméstica, varones y mujeres asumieron al matrimonio como institución necesaria a la reproducción y la herencia de la prole legítima, cuya matriz no conllevaba, necesariamente, ni el amor ni la armonía entre los convocados.

\section{REFERENCIAS BIBLIOGRÁFICAS}

ArIES, Philippe - Duby, Georges (dirs.)

1989 Historia de la vida privada. De la Revolución Francesa a la Primera Guerra Mundial, tomo 4. Madrid. Taurus.

Arellano, Ignacio - Usunáriz, Jesús María (eds.) 2005 El matrimonio en Europa y el mundo Hispánico, siglos XVI-XVII. Madrid. Visor Libros.

Arrom, Silvia Marina

1985 The Women of Mexico City, 1790-1857. Stanford. Stanford University Press.

Arroyo Vozmediano, Julio Luis

2008 “Iglesia, mujeres y violencia: Calahorra 1643-1713”. Kalakoricos. Calahorra, 13, pp. 119-146.

BOURDIEU, Pierre

1977 Outline of a Theory of Practice. Cambridge. Cambridge University Press.

1980 The Logic of Practice. Stanford. Stanford University Press.

Bustamante Otero, Luis

2001 “"El pesado yugo del santo matrimonio': divorcio y violencia conyugal en el arzobispado de Lima (1800-1805)". Historica. Lima, vol. XXV, nº 1, pp. 109-160.

Calancha, Antonio de la

1976 Crónica moralizada del orden de San Agustín en el Perú, con sucesos ejemplares vistos en esta monarquía [1639]. Prado Pastor (ed.). Vol. II. Lima. Universidad Nacional Mayor de San Marcos.

Castañeda Delgado, Paulino - Hernández Aparicio, Pilar 
1989 La Inquisición de Lima (1570-1635). Tomo I. Madrid. Demos.

Cavieres F., Eduardo - Salinas Meza, René

1991 “Amor y conflicto: unión y desunión de la pareja en los siglos XVII y XIX”. En CAVIERES - SAlinas, Amor, sexo y matrimonio en Chile tradicional. Valparaíso. Instituto de Historia de la Universidad Católica, pp. 77-116.

Costa, Marie

2008 "Divorciarse en Cataluña a finales del Antiguo Régimen: ¿rechazo o solidaridad social?" Nuevo Mundo Mundos Nuevos. Colloques. Familia y organización social en Europa y América siglos XV-XX. (Murcia - Albacete, 12-14 diciembre 2007). Paris, pp. 1-14. https://nuevomundo.revues.org/27702

DÁvila Mendoza, Dora

2004 "Vida matrimonial y orden burocrático. Una visión a través de El Cuaderno de los divorcios, 1745 a 1820, en el arzobispado de la ciudad de México". En DÁvILA (coord.), Historia, género y familia en Iberoamérica (siglos XVI al XX). Caracas. Fundación Konrad Adenauer - Universidad Católica Andrés Bello, pp. 161-207.

DÁvila MendozA, Dora (coord.)

2004 Historia, género y familia en Iberoamérica (siglos XVI al XX). Caracas. Fundación Konrad Adenauer-Universidad Católica Andrés Bello.

FERNÁNDEZ, Ana María

2013 "Femicidios: la ferocidad del patriarcado". En FERnÁNDEZ - SiQUEIRA PERES, La diferencia desquiciada. Géneros y diversidades sexuales. Buenos Aires. Editorial Biblos, pp. 171-194.

FERnÁndez, Ana María - SiqueIra Peres, Wiliam (eds.)

2013 La diferencia desquiciada. Géneros y diversidades sexuales. Buenos Aires. Editorial Biblos.

Flores Galindo, Alberto - Chocano, Magdalena

1984 "Las cargas del sacramento". Revista Andina. Cusco, no 2:2, pp. 403-422.

Franchin, Ana T.

2009 "Historia de familias, violencia doméstica en el San Juan colonial". La Aljaba. Luján (Argentina), vol. 13, no 13, ene/dic. En http://www.scielo.org.ar/scielo. php?script $=$ sci_arttext\&pid=S1669-57042009000100003

GÁLvez Ruiz, María Ángeles

2006 "La historia de las mujeres y de la familia en el México colonial. Reflexiones sobre la historiografía mexicanista". Chronica Nova. Granada, 32, pp. 67-93.

Garcia Quintanilla, Mons. Julio

1963 Historia de la Iglesia de los Charcas o La Plata. Tomo III. Sucre. Talleres Gráficos Don Bosco.

GhiRARDI, M. Mónica

2004 Matrimonios y familias en Córdoba 1700-1850. Córdoba. Centro de Estudios Avanzados.

GHIRARDi, María Mónica - LóPEz IRIGoyen, Antonio

2009 "El matrimonio, el concilio de Trento e Hispanoamérica”. Revista de Indias. Madrid, vol. LXIX, ${ }^{\circ} 246$, pp. 253-254. 
Gonzalbo Aizpuru, Pilar - Rabell, Cecilia (comps.)

1994 La familia en el mundo iberoamericano. México. Instituto de Investigaciones Sociales - Universidad Nacional Autónoma de México.

GonzÁlez del Riego E., Delfina

1995 "La sociedad colonial limeña en el siglo XVI". Histórica. Lima, vol. XIX, n 2, pp. 197-217.

1999 “El divorcio en la sociedad colonial limeña”. En Zegarra, Mujeres y Género en la Historia del Perú. Lima. CENDOC-MUJER, Centro de Documentación sobre la Mujer, pp. 131-142.

KLUGER, Viviana

2003a "Casarse, mandar y obedecer en el Virreinato del Río de la Plata: un estudio del deber-derecho de obediencia a través de los pleitos entre cónyuges". Fronteras de la Historia. Bogotá, no 8, pp. 131-151.

2003 b "Amar, honrar y obedecer en el Virreinato del Río de la Plata: de las reyertas familiares a los pleitos judiciales". Anuario Mexicano de Historia del Derecho. México D. F., $n^{\circ} 15$, pp. 525-544.

2004 "El proyecto familiar en litigio. Espacios femeninos y contiendas conyugales en el virreinato del Río de la Plata, 1776-1810”. En DáviLA (coord.), Historia, género y familia en Iberoamérica (siglos XVI al XX). Caracas. Fundación Konrad AdenauerUniversidad Católica Andrés Bello, pp. 209-246.

LANGUE, Frédérique

2005 "Las ansias del vivir y las normas del querer. Amores y "mala vida" en Venezuela colonial”. Nuevo Mundo Mundos Nuevos. París, pp. 1-16. En https://nuevomundo. revues.org/639

LATASA, Pilar

2005 "La celebración del matrimonio en el virreinato peruano: disposiciones sinodales en las archidiócesis de Charcas y Lima (1570-1613)”. En ArELlano - UsunÁRIz (eds.), El matrimonio en Europa y el mundo Hispánico, siglos XVI-XVII. Madrid. Visor Libros, pp. 237-256.

LAVALLÉ, Bernard

1999a Amor y opresión en los Andes coloniales. Lima. Instituto de Estudios Peruanos.

1999b "Divorcio y nulidad de matrimonio en Lima (1650-1700)" [1986]. En LAVALLÉ, Amor y opresión en los Andes coloniales. Lima. Instituto de Estudios Peruanos, pp. 19-66.

LAVRIN, Asunción (coord.)

1991 Sexualidad y matrimonio en la América hispánica. Siglos XVI-XVIII. México. Grijalbo.

LóPez Alarcón, Mariano

1963 La disolución del matrimonio en Derecho canónico y sus efectos civiles. Murcia. Universidad de Murcia.

MaLlo, Silvia

1992 "Justicia, divorcio, alimentos y malos tratos en el Río de la Plata, 1766-1857". Investigaciones y Ensayos. Buenos Aires, no 42, pp. 373-400.

MeJia CARrillo, Yolanda

1997 “Divorcio en Lima del siglo XVII (1700-1750)”. Alma Mater. Lima, n 13-14, pp. 57-62. 
Millar C., René

1997 Inquisición y Sociedad en el Virreinato Peruano. Santiago. Universidad Católica de Chile - Instituto Riva Agüero.

Molina, Raúl

1985 La familia porteña en los siglos XVII y XVIII. Historia de los divorcios en el período hispánico. Buenos Aires. Fuentes Históricas y Genealógicas Argentinas.

Nizza da Silva, María Beatriz

1991 "Divorcio en el Brasil colonial: el caso de São Paulo". En LaVRIN (coord.), Sexualidad y matrimonio en la América hispánica. Siglos XVI-XVIII. México. Grijalbo, pp. 339-371.

PARTIDAS

1861 Las Siete Partidas del Rey Don Alfonso X El Sabio, cotejadas con varios códices antiguos por la Real Academia de la Historia y glosadas por el Lic. Gregorio López [1265]. París. Librería de Rosa y Bouret.

PESCADOR C., Juan Javier

1994 "Entre la espada y el olivo: pleitos matrimoniales en el provisorato eclesiástico de México, siglo XIIII". En Gonzalbo AizPURU - RABEll (comps.), La familia en el mundo iberoamericano. México. Instituto de Investigaciones Sociales - Universidad Nacional Autónoma de México, pp. 193-226.

Perrot, Michèle

1989 “Dramas y conflictos familiares". En ArIES - Duby (eds.), Historia de la vida privada. De la Revolución Francesa a la primera Guerra Mundial. Tomo 4. Madrid. Taurus, pp. 269-291.

Presta, Ana María

2000a Encomienda, familia y negocios en Charcas colonial. Los encomenderos de La Plata, 1550-1600. Lima. Banco Central de la Reserva del Perú - Instituto de Estudios Peruanos.

2000b "Portraits of Four Women: Traditional Female Roles and Transgressions in Colonial Elite Families in Charcas, 1550-1600". Colonial Latin American Review. New York, vol. $9, n^{\circ} 2$, pp. 237-262.

2010 "Desde la Plaza a los Barrios. Pinceladas étnicas tras las casas y las cosas. Españoles e indios en la ciudad de La Plata, Charcas 1540-1620". Nuevo Mundo Mundos Nuevos. París, $\mathrm{n}^{\circ}$ 10. En http://nuevomundo.revues.org/index58926.html

RíPODAS ArdanAz, Daisy

1977 El Matrimonio en Indias, realidad social y regulación jurídica. Buenos Aires. Fundación para la Educación, la Ciencia y la Cultura.

RoJAs, María Teresa

1999 "Agresión de hombre, defensa de mujer: una aproximación a la violencia conyugal y la justicia en el mundo popular. Zona Central de Chile 1760-1830". Revista de Historia Social y de las Mentalidades. Santiago de Chile, nº 3:3, pp. 89-116.

Salinas Meza, René

1991 "La violencia conyugal y el rol de la mujer en la sociedad chilena tradicional. Siglos XVIII y XIX". En NúÑEZ SÁNCHEZ (ed.), Historia de la mujer y de la familia. Quito. Editora Nacional-ADHILAC, pp. 37-67.

1994 "Uniones ilegítimas y desuniones legítimas. El matrimonio y la formación de la pareja en Chile colonial". En Gonzalbo AizPuru - Rabell (comps.), La familia en el mundo iberoamericano. México D. F. Universidad Autónoma de México, pp. 173-192. 


\section{SAN PABLO}

1964 Cartas [c. 61-62]. Epístola a los Efesios. Instrucciones para cada estado. Las mujeres y los hombres, 5, 22-24. Sagrada Biblia. Barcelona. Herder, pp. 1403-1404.

Stavig, Ward

1984 "Comentarios a "Las cargas del sacramento"”. Revista Andina. Cusco, no 2:2, pp. 428-430.

1996 Amor y violencia sexual: valores indigenas en la sociedad colonial. Lima. Instituto de Estudios Peruano - University of South Florida.

Van Deusen, Nancy E.

2007 Entre lo sagrado y lo mundano. La práctica institucional y cultural del recogimiento en la Lima virreinal. Lima. Fondo Editorial de la Pontificia Universidad Católica del Perú - Instituto Francés de Estudios Andinos.

ZEGARRA, Margarita (ed.)

1999 Mujeres y Género en la Historia del Perú. Lima. Centro de Documentación sobre la Mujer. 